\title{
Glyphosate adsorption onto porous clay heterostructure (PCH): kinetic and thermodynamic studies
}

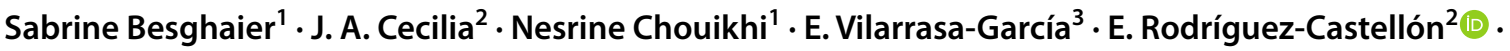 \\ Mohamed Chlendi ${ }^{1} \cdot$ Mohamed Bagane $^{1}$
}

Received: 27 June 2021 / Revised: 23 August 2021 / Accepted: 19 September 2021 / Published online: 7 October 2021

(c) The Author(s) 2021

\begin{abstract}
The synthesis of PCH from natural bentonite produces a porous heterostructure material effective for the adsorption of glyphosate from water. The adsorption process takes place through an interaction between the silanol group of montmorillonite and/or the PCH adsorbent with the functional groups of glyphosate. The glyphosate adsorption isotherms, recorded for all the studied samples, have been established to be of Langmuir type. The kinetic of the herbicide adsorption on the PCH was best described by the pseudo-second-order model. With the increase in temperature from 25 to $50{ }^{\circ} \mathrm{C}$, the sorption capacities of the materials studied towards glyphosate increased. The process of glyphosate adsorption was found to be endothermic and spontaneous in nature, as indicated by positive values of $\Delta \mathrm{H}$ and negative values of $\Delta \mathrm{G}$. According to the results obtained, the herbicide sorption was more effective in a basic environment. The maximum amount of adsorbed glyphosate is almost doubled with PCH from $13.5 \mathrm{mg} / \mathrm{g}$ of natural clay to $27.5 \mathrm{mg} / \mathrm{g}$ of PCH.
\end{abstract}

\section{Graphic abstract}

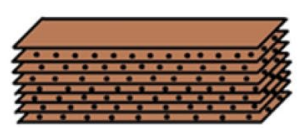

Montmorillonite

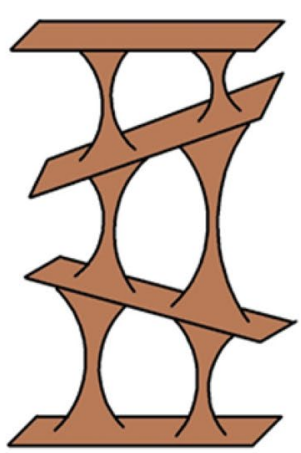

Porous Clay Heterostructure

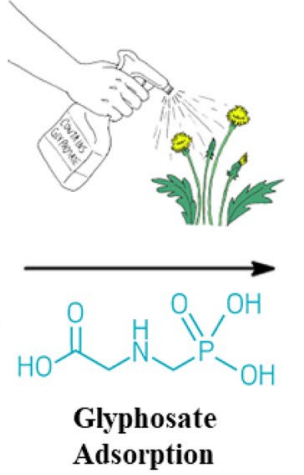

Adsorption

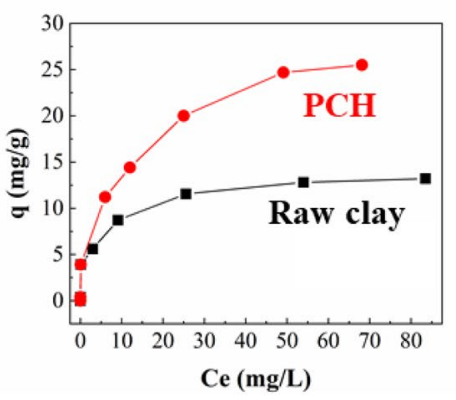

$\mathrm{Ce}(\mathrm{mg} / \mathrm{L})$

Keywords Porous clay heterostructures $\cdot \mathrm{PCH} \cdot$ Glyphosate $\cdot$ Adsorption · Organophosphate

J. A. Cecilia

jacecilia@uma.es

$\triangle$ E. Rodríguez-Castellón castellon@uma.es

1 Research Laboratory of Applied Thermodynamic, National Engineering School of Gabes, University of Gabes, 6029 Gabes, Tunisia
2 Department of Inorganic Chemistry, Crystallography and Mineralogy, Universidad de Málaga, Campus de Teatinos, 29071 Malaga, Spain

3 Department of Chemical Engineering, Grupo de Pesquisa em Separações por Adsorção, Universidade Federal do Ceará, Campus do Pici, Fortaleza, CE 60455760, Brazil 


\section{Introduction}

Research on sustainable wastewater treatment technologies has intensified in recent decades because of growing public concern about environmental issues and more severe regulations related to water pollution. Water pollution is caused by the discharge of dirty water from the domestic activities (washing and cleaning various, evacuation of domestic urine and excrements, etc.) and also by various industrial and agricultural activities which produce foods, chemicals compounds, dyes and energy. Pesticides are chemicals compounds that are used in industrial, forestry or farming sites to control of vegetation, insects and rodents (Aktar et al. 2009; Marican and Durán-Lara 2018).

According to their chemical composition, pesticides can be classified into organochlorines, organophosphorus, chlorophenols, carbamates or pyrethroids (Hamza et al. 2016; Marican and Durán-Lara 2018). These pesticides access the environment due to accidents or negligence such as percolation from storage and disposal sites in industrial facilities as well as spills in the transportation step (Khan et al. 2004). In the case of the pesticides used to control pests in crops, they seep into soils and enter surface watercourses and groundwater (Hamza et al. 2016). Nowadays, these pesticides have affected the water tables, which causes problem for human health because these compounds are very stable and can persist for a long time in soil and water (Odukkathil and Vasudevan 2013). Also, they can cause chronic damage and anomalies in both fauna and flora (Jariyal et al. 2015).

Focusing on organophosphate compounds, these chemicals are mainly used in pest control as an alternative to chlorinated hydrocarbons, which are more persistent in the environment. Although organophosphates are considered highly effective insecticides some of them, such as sarin and VX nerve agents are extremely toxic to humans (Hayes et al. 1980). In fact, organophosphates had an exclusively military application during the Second World War due to their neurotoxic effects, being subsequently used in the agricultural industry (Eto 1974). Thus, since 1950, organophosphate compounds such as parathion and malathion have been consolidated as agricultural insecticides (Eto 1974; Wilkinson and Wilkinson 1976). These pesticides are formed by a phosphorus atom linked to 4 oxygen atoms or 3 oxygen atoms and 1 sulfur in some cases. One of the phosphorousoxygen bonds is weak and the atom of phosphorus released from this group is associated with acetylcholinesterase which is responsible for breaking down the medium of acetylcholine (it also plays an important role in the central nervous system). When the acetylcholine is destroyed, nervous hyperactivity occurs that can causes the death of animals (Eto 1974; Wilkinson and Wilkinson 1976).
Glyphosate $\left(\mathrm{C}_{3} \mathrm{H}_{8} \mathrm{NO}_{5} \mathrm{P}\right)$ was introduced as a nonselective herbicide in the 1970s, and has become one of the most extensively used herbicides worldwide (Wang et al. 2016). Recently, glyphosate has been reported to be very harmful as it is involved in many maladies such as Alzheimer and Parkinson's disease, depression, cancer, infertility including genotoxic effects. The International Agency for Research on Cancer (IARC) has classified glyphosate as a 37 "probable human carcinogen" due to its mutagenic, genotoxic, and carcinogenic effects which explains the fact that the use of this herbicide is banned in 17 countries in the world as Belgium, France, Italy, USA, Oman Saudi Arabia Kuwait Emirates and United Arab (Sarkar and Das 2017).

There are many procedures for waste treatment such as photocatalytic degradation, combined photo-Fenton, biological oxidation, advanced oxidation processes, aerobic degradation, nano-filtration membranes and ozonation (Marican and Durán-Lara 2018). However, these methods are not the solution due to their high cost and low efficiency on a larger scale. Adsorption is one of the most important processes for the removal of pesticides due to its mechanical stability, low specificity, fast kinetics adsorption and high adsorption capacity (Halim et al. 2010). In this sense, it has been reported that porous carbons such as carbon nanotubes (Dehghani et al. 2017; Sarkar and Das 2017), biochar (Jiang et al. 2018), activated carbon prepared from Lawsonia inermis wood (Omri et al., 2016) or graphenebased composites (Suo et al. 2018; Yang et al. 2017), metal organic frameworks (MOFs) (Jamali et al. 2019; Yang et al. 2018a), mesoporous silica (Chen et al. 2020) or calcium alginate hydrogel fibers decorated with zirconium nanoparticle s (Zare et al. 2016). Most of these adsorbents are very effective on a laboratory scale. However, the synthesis of materials in industry can cause a reduction of the textural properties at such a high cost due to the complicated process.

That is why it is necessary to develop low-cost adsorbents to have a competitive and sustainable adsorption process. Therefore, clay minerals have emerged as a suitable choice due to their excellent performance in the areas of adsorption and catalysis for many industrial applications. In addition, the high availability, stability, abundance of unlimited applicability in the field of water and gas treatment gives them potential for use in pesticide removal processes (Adeyemo et al. 2017; Zhu et al. 2016).

Generally, the partial substitution of $\mathrm{Si}^{4+}$-species by $\mathrm{Al}^{3+}$-species generates a positive charge deficiency in the tetrahedral sheet, which is counterbalanced with the incorporation of alkaline cations in the interlayer spacing. Therefore, these phyllosilicates display a good cationic exchange capacity and layer expansion capacity (Brigatti et al. 2013). This proves that adsorption of pesticides is feasible on clay minerals because it is an inexpensive and environmentally friendly adsorbent. These materials can 
be modified by intercalation of cationic compounds, heat treatment and acid activation to improve their textural properties (Cecilia et al. 2018b; Vaccari 1999).

The porous clay heterostructure (PCH) was first described by Galarneau et al. (1995) using similar templates as previously reported for mesoporous silicas as MCM-family (Beck et al. 1992). The synthesis of PCHs begins with an exchange of an alkaline cation, which is located in the interlayer space for a bulky cation (cationic surfactant), subsequently, a source of silicon is added as an alkoxide and it expands around the cationic surfactant. Finally, a porous material is produced after calcination to remove organic matter. This material, $\mathrm{PCH}$, plays the role of an excellent adsorbent or catalytic support since it combines micro and mesoporosity in its framework (Cecilia et al. 2015, 2018a, c). In the adsorption field, PCHs have been used for the adsorption of molecules with variable dimensions. Thus, these materials have been used in the $\mathrm{CO}_{2}$ adsorption (Vilarrasa-García et al. 2017), the selective separation of small hydrocarbons (Pires et al. 2004, 2008), volatile organic compounds (Ferreira et al. 2006; Nunes et al. 2008), drugs (Gârea et al. 2015) and dyes (Aguiar et al. 2017).

The aim of this work is the synthesis of PCHs from natural Tunisian clay for the adsorption of glyphosate. The prepared materials were characterized by XRD, FTIR, TGA, XPS and BET measurements.

\section{Materials and methods}

\section{Reagents}

All of the reagents used in the present study were of analytical grade and used without further purification: sulfuric acid (95-98\%, Aldrich), hexadecyltrimethylammonium bromide (99\%, Aldrich), anhydrous n-propanol (99.9\%, VWR), hexadecylamine (90\%, Aldrich), tetraethylorthosilicate (98\%, Aldrich), ethanol (96\%, Aldrich). The glyphosate was supplied for LGC, Dr. Ehrenstorfer (Purity: 98.6\%).

\section{Clay minerals}

The clay was collected from "Jebel Al Aidoudi in El Hamma-Gabes" (Tunisia). For purification, the clay was suspended in deionized water for $24 \mathrm{~h}$ to obtain the clay fraction $(<2 \mu \mathrm{m})$. After washing, a wet sieving was performed to remove sterile and crystalline phases. In the next step, the clay was then dried at $105{ }^{\circ} \mathrm{C}$ in the oven for $24 \mathrm{~h}$. Finally, the dried clay is crushed and sieved at $40 \mu \mathrm{m}$.

\section{Synthesis of the PCHs}

The synthesis of PCHs was carried out according the procedure proposed by Cecilia et al. elsewhere (Cecilia et al. 2013).

To increase the interlayer space, $5 \mathrm{~g}$ of Na-montmorillonite were mixed with $18 \mathrm{~g}$ of hexadecyltrimethylammonium bromide (HDTM-Br) in $200 \mathrm{~mL}$ of n-propanol. After stirring for $72 \mathrm{~h}$, the suspension has undergone a filtration and washing with deionized water until the $\mathrm{pH}$ was neutral to remove the non-intercalated $\mathrm{HDTM}^{+}$. Then, the solid was re-suspended in $500 \mathrm{~mL}$ of water and stirred for $24 \mathrm{~h}$. After this time, a solution of $1.8 \mathrm{~g}$ of hexadecylamine (used as co-surfactant) and $50 \mathrm{~mL}$ of $n$-propanol were added to the mother solution and stirred for $24 \mathrm{~h}$. In the next step, $25 \mathrm{~mL}$ tetraethylorthosilicate (TEOS) were dissolved in $25 \mathrm{ml}$ $n$-propanol and added to the mother solution to form the silica-pillars around the co-surfactant in the interlayer spacing of montmorillonite. The obtained gel was stirred during $72 \mathrm{~h}$ and then was filtered and washed with water-ethanol and dried at $60{ }^{\circ} \mathrm{C}$ in air for $12 \mathrm{~h}$. Finally, the surfactant was removed by calcination at $550{ }^{\circ} \mathrm{C}$ with a heating rate of $1{ }^{\circ} \mathrm{C} \mathrm{min}{ }^{-1}$ during $6 \mathrm{~h}$.

\section{Characterization of the adsorbents}

X-ray diffractograms were collected on an automated X'Pert Pro MPD (PANalytical BV) diffractometer equipped with a Ge (111) primary monochromator (strictly monochromatic $\mathrm{Cu} \mathrm{K} \alpha 1$ radiation) and an $\mathrm{X}^{\prime}$ Celerator detector with a step of $0.017^{\circ}$ working at $45 \mathrm{kV}$ and $40 \mathrm{~mA}$. The powder profiles were recorded between $10^{\circ}$ and $70^{\circ}$ in $2 \theta$ with a total measurement time of $30 \mathrm{~min}$. Low angle measurements were obtained with the same configuration maintaining divergence and anti-divergence aperture at $1 / 16^{\circ}$ and with Soller of 0.02 rad.

Attenuated total reflectance (ATR) was performed using a Bruker's Vertex70 FT-IR spectrophotometer model. The spectral acquisition was carried out using a standard spectral resolution of $4 \mathrm{~cm}^{-1}$ and 64 accumulations in the range (4000-500 $\mathrm{cm}^{-1}$ ).

The textural properties of the starting clay and the PCHs were determined by the $\mathrm{N}_{2}$ adsorption-desorption at -196 ${ }^{\circ} \mathrm{C}$ by an automatic ASAP 2420 system from Micromeritics. Before the measurements, samples were outgassed at $200{ }^{\circ} \mathrm{C}$ and $10^{-4}$ mbar overnight. The specific surface area was estimated from the Brunauer-Emmett-Teller (BET) equation considering a $\mathrm{N}_{2}$ cross section of $16.2 \AA^{2}$ (Brunauer et al. 1938). The total pore volume was calculated from the adsorption isotherm at $\mathrm{P} / \mathrm{P}_{0}=0.996$. Micropore volume was determined was determined from the t-plot method from Lippens and De Boer calculations (Lippens and De Boer 
1965). Pore size distribution was determined using the density functional theory (DFT) (Landers et al. 2013).

Differential thermal analysis (DTA) and thermogravimetry analysis (TGA) data were taken on a Mettler-Toledo (TGA/DSC 1) analyzer from RT instruments (New Castle, $\mathrm{DE})$. The temperature was varied from RT to $1000{ }^{\circ} \mathrm{C}$ at a heating rate of $5{ }^{\circ} \mathrm{C} \mathrm{min}^{-1}$. Measurements were carried out on samples in open platinum crucibles under air flow.

The surface of the studied solids was studied by X-Ray Photoelectron Spectroscopy (XPS) with a Physical Electronic PHI 5700 spectrometer using non monochromatic $\mathrm{Mg}-\mathrm{K} \alpha$ radiation $(300 \mathrm{~W}, 15 \mathrm{kV}, 1253.6 \mathrm{eV})$. The spectra of powdered samples were registered with a constant pass energy values at $29.35 \mathrm{eV}$, using a $720 \mu \mathrm{m}$ diameter circular analysis area. The XPS spectra obtained were analyzed with PHI ACESS ESCA-V6.0F software and processed using Multipak $8.2 B$ package. The binding energy values were referenced to C $1 s$ signal $(284.8 \mathrm{eV})$. Shirley type background and Gauss-Lorentz curves were used to determinate the binding energy.

\section{Adsorption experiments}

All adsorption experiments were realized at $22{ }^{\circ} \mathrm{C}$. Batch experiments were carried out to study the impact of $\mathrm{pH}$, adsorbent mass, contact time as well as adsorption isotherms. After preparing a pesticide stock solution with a concentration of $100 \mathrm{mg} / \mathrm{L}$, adsorption experiments were performed in a rotatory shaker. For this aim, $40 \mathrm{mg}$ of $\mathrm{PCH}$ were added to $50 \mathrm{~mL}$ conical tubes containing $10 \mathrm{~mL}$ of glyphosate solution. At the end of each experiment, the supernatant was collected and centrifuged for $15 \mathrm{~min}$.

The $\mathrm{pH}$ of each pesticide solution was adjusted using $0.1 \mathrm{~mol} / \mathrm{L}$ of $\mathrm{NaOH}$ and $0.1 \mathrm{~mol} / \mathrm{L}$ of $\mathrm{HCl}$. The adsorption of glyphosate on $\mathrm{PCH}$ was carried out in $\mathrm{pH}$ range of 2 to 12 , PCH dosage (10-50 mg), stirring rate $(50-400 \mathrm{rpm})$, initial glyphosate concentration (20-100 mg/L) and contact time (10-120 $\mathrm{min})$.

The concentration of pesticide in liquid phase (supernatant) was determined by liquid chromatography-mass spectrometry (HPLC). The analysis instrument is equipped with a Dionex Ultimate 3000 liquid chromatograph (Thermo Scientifics), an H-ESI II ionization source (electrospray) and a TSQ Quantum Access triple quadrupole mass spectrometer. During preparation before injection, $15 \mu \mathrm{L}$ of each sample is taken and diluted to $5 \mathrm{ml}$ with milli-Q water. The samples are filtered with a $25 \mu \mathrm{m}$ nylon filter. In the quantitative determination, standard glyphosate (99.7\%) and glyphosate 2-13C were used as internal standard (IS) (Sigma Aldrich). The standards were prepared in mili-Q water at a concentration of $1 \mathrm{mg} \mathrm{mL}^{-1}$.

The liquid chromatograph operates with a hypercarb column $(5 \mu \mathrm{m} \times 100 \mathrm{~mm} \times 2.1 \mathrm{~mm})$ (Thermo Scientifics).
The injection volume is $5 \mu \mathrm{L}$. Mobile phase A: $1 \%$ formic acid in acetonitrile. Mobile phase B: $1 \%$ formic acid in milli Q water. Mobile phase C: $95 \%$ methanol and 5\% milli Q. water. The flow rate of the mobile phase is $300 \mu \mathrm{L} / \mathrm{min}$ with an A gradient from 0 to $80 \%$ at $0.5 \mathrm{~min}$, remaining $2.5 \mathrm{~min}$. Then a regeneration of the column is carried out for 3 min with $100 \%$ of phase C.

The mass spectrometer has a spraying voltage $4500 \mathrm{~V}$, sheath gas 35 , auxiliary gas 10 , sweeping gas $0, \mathrm{~T}$-shaped lens 80 , capillary temperature $350^{\circ} \mathrm{C}$ and auxiliary gas temperature $230^{\circ} \mathrm{C}$.

Using a syringe pump, a glyphosate standard and the internal standard were injected into the mass spectrometer. The transitions from the father ion to the son ion have been optimized using the automatic optimization function of the TraceFinder software, $\lambda_{\text {glyphosate }}=220 \mathrm{~nm}$.

The amount of glyphosate adsorbed (adsorption capacity q) was calculated by using the following mass balance:

$q=\frac{\left(C_{0}-C_{e}\right) \times V}{m}$

$C_{0}$ is the initial liquid concentration of glyphosate $\left(\mathrm{mg} \mathrm{mL}^{-1}\right), \mathrm{C}_{\mathrm{e}}$ is the equilibrium liquid concentration of glyphosate $\left(\mathrm{mg} \mathrm{mL}^{-1}\right), V$ is the volume solution $(\mathrm{mL})$ and $m$ is the mass adsorbent $(\mathrm{g})$.

\section{Modeling of adsorption isotherms}

The Langmuir model describes the equilibrium distribution of the adsorbed ions between the solid and liquid phases. This isotherm is valid for monolayer adsorption on a surface containing a precise number of similar sites. The linear form of Langmuir equation is defined by the equation below (Al-Ghouti and Da'ana 2020):

$\frac{C_{e}}{q_{e}}=\frac{1}{Q_{0} b}+\frac{1}{Q_{0}} C_{e}$

where $\mathrm{q}_{\mathrm{e}}(\mathrm{mg} / \mathrm{g})$ is the amount of adsorbed glyphosate per unit mass of adsorbent and $\mathrm{C}_{\mathrm{e}}$ is the glyphosate concentration at the equilibrium. $\mathrm{Q}_{0}$ is the maximum amount of the glyphosate per unit mass of adsorbent to form a complete monolayer on the surface bound at high $\mathrm{C}_{\mathrm{e}}$ and $\mathrm{b}$ is a constant related to the affinity of the binding sites $(\mathrm{L} / \mathrm{mg})$.

The essential characteristics of the Langmuir model can be described by an additional constant called the separation factor $\mathrm{R}_{\mathrm{L}}$ (also called the equilibrium parameter) (Al-Ghouti and Da'ana 2020). This factor is defined by the following equation: 
$R_{L}=\frac{1}{1+b C_{0}}$

where $\mathrm{C}_{0}$ is the highest initial concentration of Glyphosate.

If $\mathrm{R}_{\mathrm{L}}=0$, the adsorption is irreversible.

If $0<R_{L}<1$, the adsorption is favorable.

If $\mathrm{R}_{\mathrm{L}}=1$, the adsorption is linear.

If $\mathrm{R}_{\mathrm{L}}>1$, the adsorption is unfavorable.

The Freundlich model represents the adsorption on a heterogeneous surface and it is described with the following linear form (Al-Ghouti and Da'ana 2020):

$\ln q_{e}=\ln K_{F}+\left(\frac{1}{n}\right) \ln C_{e}$

where $\mathrm{K}_{\mathrm{f}}(\mathrm{L} / \mathrm{mg})$ and $n$ are Freundlich constants with $\mathrm{K}_{\mathrm{F}}$ is the adsorption capacity of the sorbent and $\mathrm{n}$ giving an indication of the adsorption process favorability (Al-Ghouti and Da'ana 2020).

The Temkin model is known with the linear form, which is presented by the equation below:

$q_{e}=B \ln A+B \ln C_{e}$

This model has an isotherm constant $\mathrm{A}(\mathrm{L} / \mathrm{g})$ and a sorption heat constant $b(\mathrm{~J} / \mathrm{mol})$ where $B=R T / b$; $R$ is the gas constant $(8.314 \mathrm{~J} / \mathrm{mol} \mathrm{K})$ and $\mathrm{T}(\mathrm{K})$ is the absolute temperature.

\section{Adsorption kinetics}

Lagergren proposed a method for adsorption analysis, which is the pseudo-first-order kinetic equation in the linear form (Vaccari 1999).

$\log \left(q_{e}-q_{t}\right)=\log q_{e}-\left(\frac{k_{1}}{2.303}\right) t$

where $\mathrm{q}_{\mathrm{e}}$ and $\mathrm{q}_{\mathrm{t}}$ are the amount of glyphosate adsorbed $(\mathrm{mg} / \mathrm{g})$ at the equilibrium and at an instant $\mathrm{t}(\mathrm{min})$ and $\mathrm{k} 1$ is the pseudo-first-order rate constant $(1 / \mathrm{min})$.

A linear plot of $\ln \left(\mathrm{q}_{\mathrm{e}}-\mathrm{q}_{\mathrm{t}}\right)$ against time allows was found with a good correlation coefficient. The Lagergren's firstorder rate constant $\left(\mathrm{k}_{1}\right)$ and $\mathrm{q}_{\mathrm{e}}$ determined from the model are presented in Table 4 together with the corresponding correlation coefficients.

The pseudo-second-order kinetic model was proposed by Blanchard with and presented with the following equation in the linear form (Galarneau et al. 1995):

$\frac{t}{q_{t}}=\frac{1}{k_{2} q_{e}^{2}}+\frac{1}{q_{e}} t$ where $\mathrm{k}_{2}(\mathrm{~g} / \mathrm{mg} \mathrm{h})$ is the rate constant of adsorption, $\mathrm{q}_{\mathrm{e}}$ $(\mathrm{mg} / \mathrm{g})$ is the amount of glyphosate adsorbed at equilibrium and $\mathrm{q}_{\mathrm{t}}(\mathrm{mg} / \mathrm{g})$ is the amount of glyphosate adsorbed at time $\mathrm{t}$. The equilibrium adsorption capacity $\left(\mathrm{q}_{\mathrm{e}}\right)$, and the secondorder constants $\mathrm{k}_{2}$ (g/mg min) can be determined experimentally from the slope and intercept of plot $t / \mathrm{q}_{\mathrm{t}}$ versus $\mathrm{t}$.

\section{Results and discussion}

\section{Characterization}

The structure of the clay and PCH was analyzed by XRD and illustrated in Fig. 1. For the raw clay, $\mathrm{d}_{001}$ diffraction peak can be observed at $2 \theta=7.7^{\circ}(11.7 \mathrm{~nm})$. This indicates that the cations located in the interlayer spacing are partially solvated since the interlaminar spacing usually oscillates between $10 \mathrm{~nm}$ for the anhydrous clay and $14 \mathrm{~nm}$ in the case of clay with fully solvated cations (Cecilia et al. 2018a). Other diffraction lines that have been considered in the literature for smectites are located at $2 \theta=19.9^{\circ}, 34.9^{\circ}$ and $62.1^{\circ}$ (Cecilia et al. 2013). Among them, the latter diffraction peak is very useful since it is possible to discern between a dioctahedral and trioctahedral smectites. In the case of the clay of this research, the $\mathrm{d}_{060}$ reflection appears at $2 \theta=62.1^{\circ}(1.49 \mathrm{~nm})$. This indicates the presence of a dioctahedral clay, i.e. Al-rich smectite since the trioctahedral clay (Mg-rich smectite) should appear at $1.52 \mathrm{~nm}$. In addition, the presence of narrower peaks also suggests the existence of impurities in the Al-rich smectite. Thus, it is noteworthy the presence of a peak located at $2 \theta=26.6^{\circ}$, which is assigned of the existence of quartz. The presence of the other peaks is assigned of other impurities such as calcite or plagioclases.

The inclusion of a bulky cation and the formation of silica pillars should modify the basal diffraction peaks. However,

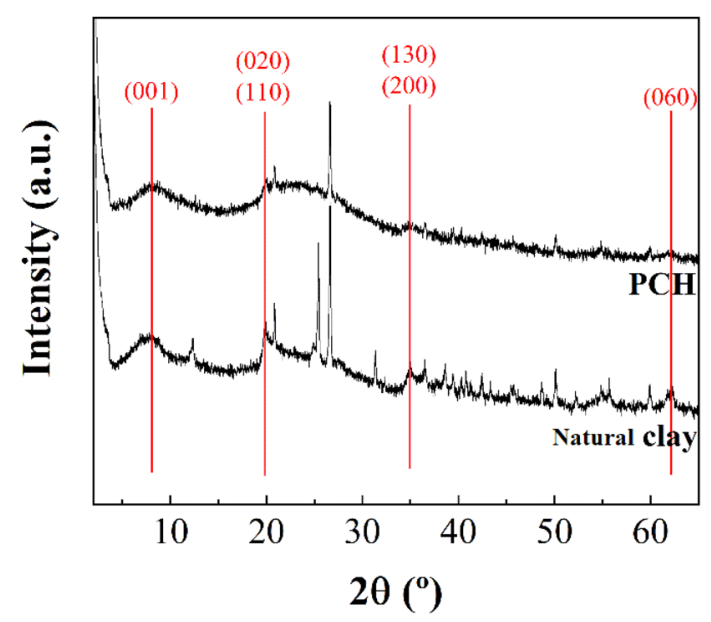

Fig. 1 XRD pattern of the Natural Clay raw clay and PCH 


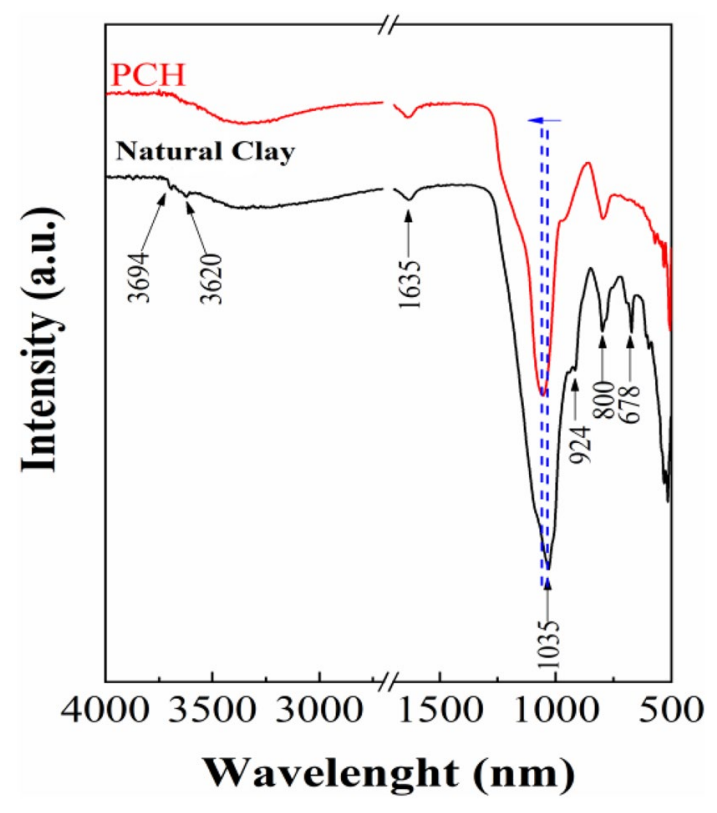

Fig. 2 FTIR-ATR spectra of Natural Clay and PCH

basal reflections such $\mathrm{d}_{001}$ hardly change. Nevertheless, it is striking that the diffraction peaks are less intense after the insertion of the pillars, probably due to a partial delamination of the smectite, which causes a random displacement along the $a$ and $b$-axes leading to a house of cards structure (Vilarrasa-García et al. 2017). On the other hand, it can also be observed that the amount of crystalline impurities decreases drastically since only the presence of quartz is observed.

Figure 2 illustrates the ATR spectra of the natural clay and the $\mathrm{PCH}$. In the case of the raw clay, the $\mathrm{OH}$-stretching region shows a broad band located between 3700 and $2700 \mathrm{~cm}^{-1}$. In this region, it is noteworthy the presence of two bands located at 3694 and $3620 \mathrm{~cm}^{-1}$. The band located at $3646 \mathrm{~cm}^{-1}$ is assigned to the $\mathrm{Al}(\mathrm{OH}) \mathrm{Al}$-stretching vibrations while the band at about $3694 \mathrm{~cm}^{-1}$ is attributed to the presence of pyrophyllite-like local structural fragments (Zviagina et al. 2004) or to a small amount of $\mathrm{Mg}$ in the octahedral sheet of montmorillonite (Franco et al 2016). The $\mathrm{Si}-\mathrm{O}$ stretching vibration of raw clay displays a maximum about $1035 \mathrm{~cm}^{-1}$, which is in agreement with other data described for montmorillonite previously (Madejová 2003; Zviagina et al. 2004). On the other hand, the $\mathrm{Al}_{2} \mathrm{OH}$ bending bands of montmorillonite about $924 \mathrm{~cm}^{-1}$ arises from vibrations of inner and surface $\mathrm{OH}$ groups (Madejová 2003) while the band located at $800 \mathrm{~cm}^{-1}$ is assigned to the overlapping of AlMgOH bending bands, which reflects partial substitution of $\mathrm{Al}$-species in the octahedral sites by $\mathrm{Mg}$-species (Madejová, 2003), and the $\mathrm{Fe}_{2} \mathrm{OH}$ bending bands (Madejová 2003). The band located about $678 \mathrm{~cm}^{-1}$ is attributed to $\mathrm{Fe}-\mathrm{O}$ out-of-plane vibration (Madejová 2003). Finally, the

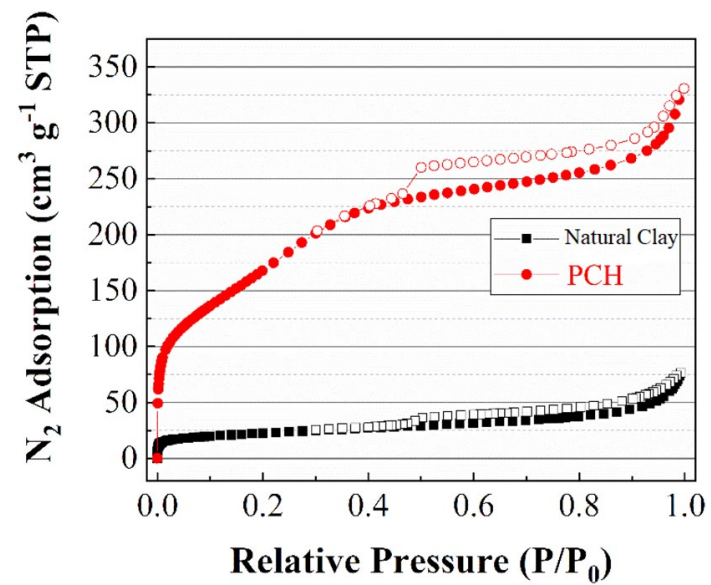

Fig. $3 \mathrm{~N}_{2}$ adsorption-desorption isotherms at $-196{ }^{\circ} \mathrm{C}$ for Natural Clay and $\mathrm{PCH}$

band located at $1635 \mathrm{~cm}^{-1}$ related to the water bending mode (Farmer 1974).

With regard to the $\mathrm{PCH}$, the bands located between $3750-3525 \mathrm{~cm}^{-1}$, assigned to the presence of silanol groups, disappear after the calcination of the organic matter. It must be considered that the combustion of organic matter is an exothermic process in such a way the - $\mathrm{OH}$ groups are probably condensed to siloxanes groups (Cecilia et al. 2013). On the other hand, it is also noteworthy that formation of silica pillars causes a slight shift of the $\mathrm{Si}-\mathrm{O}$ stretching vibration as a consequence of the formation of amorphous silica (Madejová 2003).

To evaluate the textural properties of natural clay and $\mathrm{PCH}, \mathrm{N}_{2}$ adsorption/desorption isotherms at $-196{ }^{\circ} \mathrm{C}$ on those adsorbents were carried out (Fig. 3). According to the IUPAC classification, both adsorbents can be considered as type IV, which is typical of mesoporous material, although the increase of the $\mathrm{N}_{2}$ adsorbed at high relative pressure can resemble to type II, which is typical of macroporous materials (Thommes et al. 2015). In the same way, both adsorbents also display hysteresis loops that can be fitted to $\mathrm{H}_{3}$, which are given by non-rigid aggregates of plate-like particles as clays (Thommes et al. 2015). The detailed analysis of the $\mathrm{N}_{2}$-adsorption isotherms reveals that $\mathrm{PCH}$ adsorbs high amount of $\mathrm{N}_{2}$ at lower relative pressure. This indicates that PCH displays higher micro-porosity than its corresponding natural clay. These data are in agreement with the literature since these materials have been used in adsorption processes for small molecules such as $\mathrm{CO}_{2}$ or small hydrocarbons (Pires et al. 2008; Vilarrasa-García et al. 2017). At higher relative pressure, the increase of the $\mathrm{N}_{2}$-adsorbed mainly for $\mathrm{PCH}$ suggests the presence of macro-porosity, which can be related to a disorder of the sheets during the formation of the $\mathrm{PCH}$. 
Table 1 Textural parameter of Natural Clay and PCH

\begin{tabular}{lllll}
\hline Sample & $\mathrm{S}_{\mathrm{BET}}\left(\mathrm{m}^{2} \mathrm{~g}^{-1}\right)$ & $\begin{array}{l}\mathrm{t}-\mathrm{plot} \\
\left(\mathrm{m}^{2} \mathrm{~g}^{-1}\right)\end{array}$ & $\begin{array}{l}\text { Pore } \\
\text { volume } \\
\left(\mathrm{cm}^{3} \mathrm{~g}^{-1}\right)\end{array}$ & $\begin{array}{l}\text { Micropore } \\
\text { volume } \\
\left(\mathrm{cm}^{3} \mathrm{~g}^{-1}\right)\end{array}$ \\
\hline Natural Clay & 69 & 38 & 0.082 & 0.018 \\
PCH & 621 & 422 & 0.441 & 0.227 \\
\hline
\end{tabular}

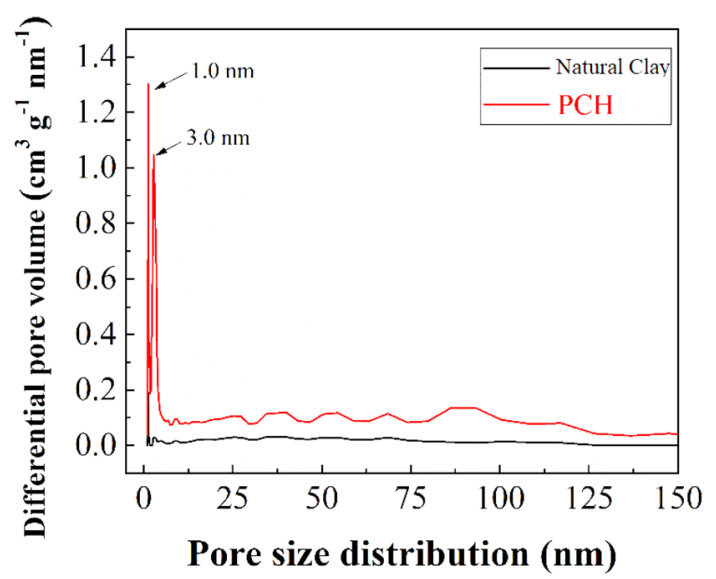

Fig. 4 Pore size distribution of PCH and Natural Clay sample

The specific surface area was determined from BET equation (Table 1) (Brunauer et al. 1938). These data show that PCH has much higher $S_{B E T}$ value than that shown by natural clay. In the same way, the PCH also displays a high microporosity in comparison to the natural clay as was inferred from its $\mathrm{N}_{2}$-adsorption isotherm. With regard to the pore volume, the data reported in Table 1 follow the same trend to that observed for the specific surface area since PCH displays higher micro- and meso-porosity.

The pore size distribution was estimated by the DFT method and was reported in Fig. 4 (Landers et al. 2013). In the case of natural clay, a maximum located about $1 \mathrm{~nm}$ can be observed, which confirms the micro-porosity of the natural clay, being in agreement with XRD data where $\mathrm{d}_{001}$ diffraction peak reported an interlayer spacing of $11.7 \mathrm{~nm}$ (Fig. 1). In the case of the pore size distribution of the PCH, two maxima located at 1.0 and $3.0 \mathrm{~nm}$ are observed so this material has a dual porosity. The greater intensity of the band whose pore distribution is $1.0 \mathrm{~nm}$ confirms the presence of large micro-porosity as a consequence of a random shifting of the sheets in the clays along the synthesis of $\mathrm{PCH}$. The signal whose pore distribution displays a maximum at $3.0 \mathrm{~nm}$ confirms the formation of a porous structure with homogeneous pore size in the $\mathrm{PCH}$ sample. From $3.0 \mathrm{~nm}$, a wide pore size distribution can be observed due to voids between adjacent particles.

The surface chemical composition of the natural clay and PCH was determined by XPS (Table 2). In the case of the raw clay, the $\mathrm{O} 1 s$ core level spectrum shows a contribution betwenn $531.8-532.1 \mathrm{eV}$ assigned to oxides species, The $\mathrm{Al}$ $2 p$ core level spectrum shows a band at $74.9 \mathrm{eV}$ while the $\mathrm{Si}$ $2 p$ core level spectrum displays a band at $103.6 \mathrm{eV}$, which are typical for $\mathrm{Al}^{3+}$ and $\mathrm{Si}^{4+}$ of clay minerals, respectively. Other contributions with lower intensities are also observed in the case of the $\mathrm{Mg} 2 p, \mathrm{Fe} 2 p$ and $\mathrm{Ca} 2 p$ core level spectra, which are assigned to $\mathrm{Mg}^{2+}, \mathrm{Fe}^{3+}$ and $\mathrm{Ca}^{2+}$ species. The analysis of the surface composition (in atomic concentration \%) reveals a high proportion of $\mathrm{Si}$ in comparison to $\mathrm{Al}, \mathrm{Fe}$ and $\mathrm{Mg}$. Thus supposes that the substitution of Si by other cations with lower charge ( $\mathrm{Al}, \mathrm{Fe}$ and $\mathrm{Mg}$ ) is relatively low so its cationic exchange capacity must also be relatively low. On the other hand, the presence of $\mathrm{Fe}$ an $\mathrm{Mg}$-species also confirms the presence of $\mathrm{AlMgOH}$ and $\mathrm{Fe}_{2} \mathrm{OH}$ bending bands shown in FT-IR section (Fig. 2).

The study of the PCH by XPS shows that the binding energy values of all the studied elements are maintained although, as expected, the atomic concentrations of these elements on the surface of the natural clay and the PCH differ between them. Thus, the analysis of the $\mathrm{Si} 2 p$ core level spectrum of the $\mathrm{PCH}$ shows a clear increase of the Si-content on its surface, which confirms the presence of silica pillars in its structure as suggested from the textural properties previously (Figs. 3, 4).

The thermogravimetric analyses of the natural clay and the PCH are shown in Fig. 5. The TG analysis of the natural clay reveals two mass losses. The first loss mass between 30 and $250^{\circ} \mathrm{C}$ is related to the progressive desorption of water molecules adsorbed on the surface of the clay and those water that interacts with the cations located in the interlayer spacing. The second mass loss, located between 400 and $700{ }^{\circ} \mathrm{C}$, corresponds to the dehydroxylation of structural $-\mathrm{OH}$ groups located between the tetrahedral sheets of $2: 1$
Table 2 Chemical surface composition (in atomic concentration \%) of the Natural Clay and PCH before and after glyphosate adsorption

\begin{tabular}{llllllll}
\hline Sample & \multicolumn{7}{l}{ Atomic concentrations $(\%)$} \\
\cline { 2 - 8 } & $\mathrm{C} 1 \mathrm{~s}$ & $\mathrm{O} 1 \mathrm{~s}$ & $\mathrm{Al} 2 p$ & $\mathrm{Si} 2 p$ & $\mathrm{Ca} 2 p$ & $\mathrm{Fe} 2 p$ & $\mathrm{Mg} 2 p$ \\
\hline Natural Clay & 7.72 & 54.26 & 2.42 & 23.23 & 0.37 & 0.60 & 0.20 \\
Natural Clay AA & 9.62 & 60.55 & 3.27 & 25.79 & 0.11 & 0.54 & 0.19 \\
PCH & 6.89 & 52.75 & 0.45 & 29.78 & - & 0.10 & 0.03 \\
PCH AA & 8.28 & 62.22 & 1.62 & 27.69 & - & 0.15 & 0.05 \\
\hline
\end{tabular}




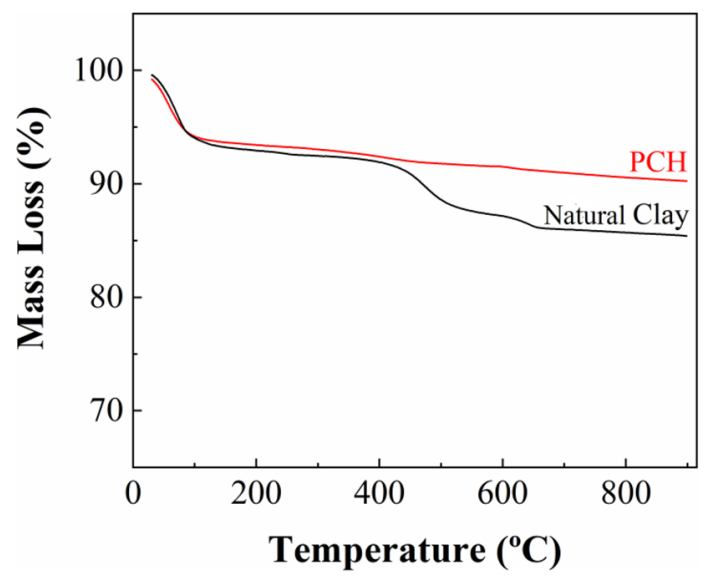

Fig. 5 Thermogravimetric analysis of the Natural Clay and PCH

bentonite layers. Considering these two steps, the loss is $15 \%$. In the case of the $\mathrm{PCH}$, the first loss ascribed to the physisorbed water is very similar to that observed in the natural clay. However, the loss, ascribed to the dehydroxylation of - $\mathrm{OH}$ groups, is not observed in such a way the mass loss is only of $10 \%$. This fact is ascribed to the calcination of the organic matter used as template in the synthesis of $\mathrm{PCH}$, which is removed at $550{ }^{\circ} \mathrm{C}$ for $6 \mathrm{~h}$ (Garea et al. 2016).

\section{Factors affecting the adsorption capacity}

Once natural clay and PCH were characterized, both materials were used as sorbent in the adsorption of glyphosate, which is considered as a harmful herbicide.

\section{Effect of the pH on glyphosate adsorption}

$\mathrm{pH}$ is one of the most important parameters affecting the quality of groundwater. In addition, $\mathrm{pH}$ is a key parameter that profoundly influences the adsorption of the pollutant onto the adsorbent.

The study of the adsorption as a function of $\mathrm{pH}$ reveals that glyphosate adsorption grows from 19.09 to $32.57 \mathrm{mg} / \mathrm{g}$ when the $\mathrm{pH}$ of the solution increases from 2 to 12 (Fig. 6). These data show how the efficiency of the glyphosate adsorption improves in an alkaline medium. Under these $\mathrm{pH}$ conditions, the $-\mathrm{O}^{-}$groups of the natural clay or $\mathrm{PCH}$ can interacts with the $-{ }^{+} \mathrm{NH}_{2}-$ groups of the glyphosate by electrostatic interaction (Khoury et al. 2010). These data are in agreement with those reported in previous investigations where the use of alkaline $\mathrm{pH}$ favors the glyphosate removal in forest soil or activated carbon (Herath et al. 2019; Sen et al. 2017).

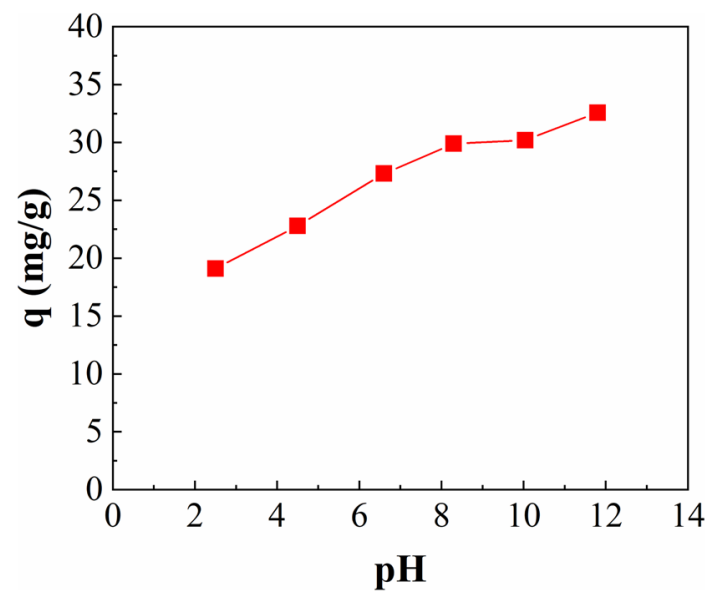

Fig. 6 Effect of the $\mathrm{pH}$ on glyphosate adsorption onto $\mathrm{PCH}$ $\left(\mathrm{m}_{\mathrm{PCH}}=40 \mathrm{mg}, \mathrm{T}=25^{\circ} \mathrm{C}\right.$ and $\left.\mathrm{C}_{\mathrm{i}}=100 \mathrm{ppm}\right)$

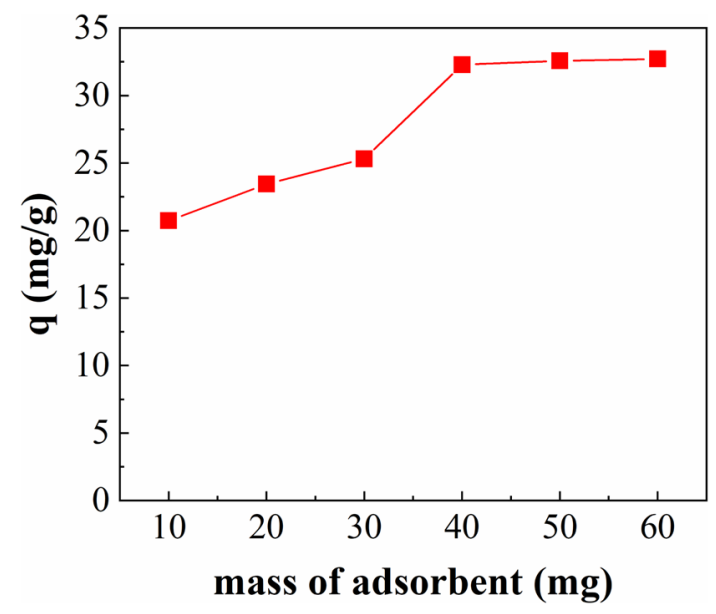

Fig. 7 Effect of the amount of $\mathrm{PCH}$ glyphosate adsorption $(\mathrm{pH}=8$, $\mathrm{T}=25^{\circ} \mathrm{C}$ and $\mathrm{C}_{\mathrm{i}}=100 \mathrm{ppm}$ )

\section{Effect of the amount of the PCH on glyphosate adsorption}

In the present study, the initial $\mathrm{pH}$ of the glyphosate solution is 8 when initial glyphosate concentration, dosage and temperature were fixed at $100 \mathrm{mg} / \mathrm{L}, 5 \mathrm{~g} / \mathrm{L}$ and $25.0{ }^{\circ} \mathrm{C}$, respectively. The effect of changing the $\mathrm{pH}$ on the adsorption capacity of glyphosate is shown in Fig. 7.

The removal of glyphosate shows gradually increases as the amount of adsorbent in the dispersion increases from 0.01 to $0.04 \mathrm{~g} / 10 \mathrm{~mL}$. This is due to the increase in available adsorption sites (Fig. 7). It is also due to the enhancement of new surface area with the increase in the amount of the adsorbent. From this point, the glyphosate adsorption capacity with a mass of $\mathrm{PCH}$ greater than $0.04 \mathrm{~g}$ is almost constant and reaches the adsorption equilibrium. 


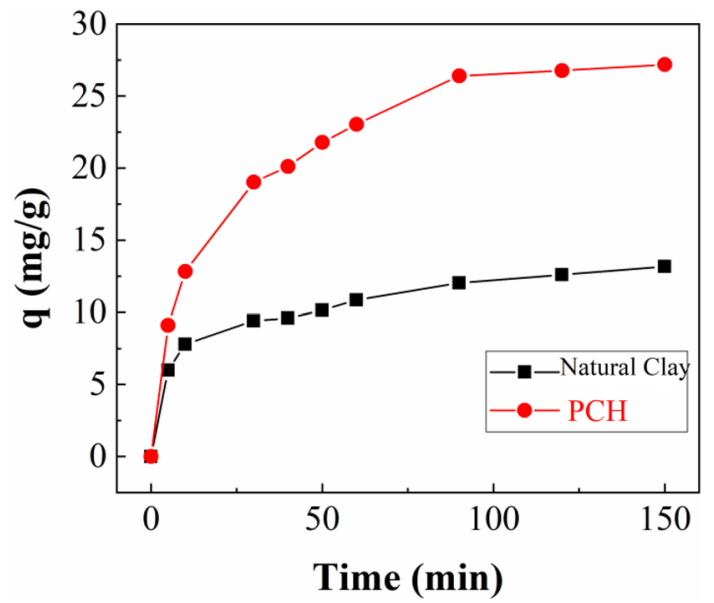

Fig. 8 Effect of contact time Glyphosate Adsorption onto Natural Clay $(\mathrm{NC})$ and $(\mathrm{PCH})$ using an initial Glyphosate concentration $100 \mathrm{ppm}$ at $\mathrm{pH}=8$ and $\mathrm{T}=25^{\circ} \mathrm{C}$

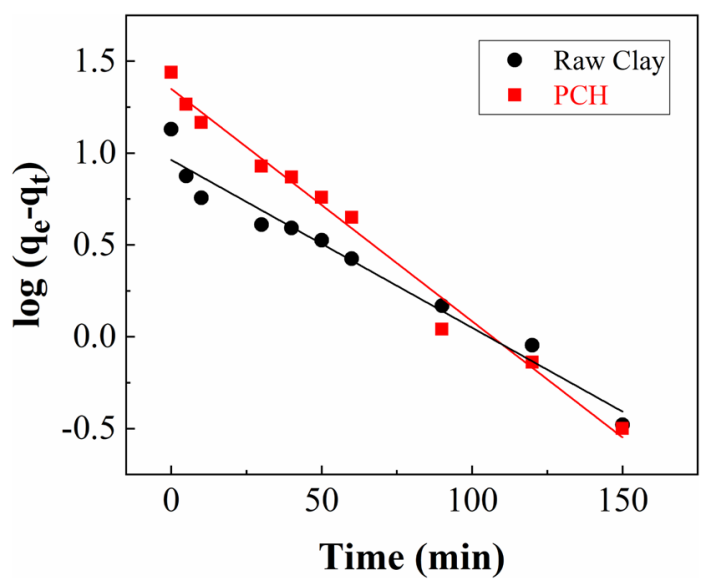

Fig. 9 Pseudo-first-order kinetic model of Glyphosate adsorption on Natural clay and PCH

\section{Adsorption kinetics}

The kinetic profiles of glyphosate in raw clay and $\mathrm{PCH}$ are shown in Fig. 8. The kinetic study displays that both the natural clay and $\mathrm{PCH}$ require similar reaction time to reach the equilibrium conditions, about $100 \mathrm{~min}$. This implies that the interaction between the adsorbate and the adsorbent must be similar in raw clay and $\mathrm{PCH}$.

The modeling of glyphosate adsorption kinetics on natural clay and $\mathrm{PCH}$ was investigated using two common models, namely the pseudo-first order model and pseudosecond-order model (Figs. 9, 10). The second-order rate constant $\left(\mathrm{k}_{2}\right)$ and $\mathrm{q}_{\mathrm{e}}$ determined from the model are presented in Table 3 along with the corresponding correlation coefficients.

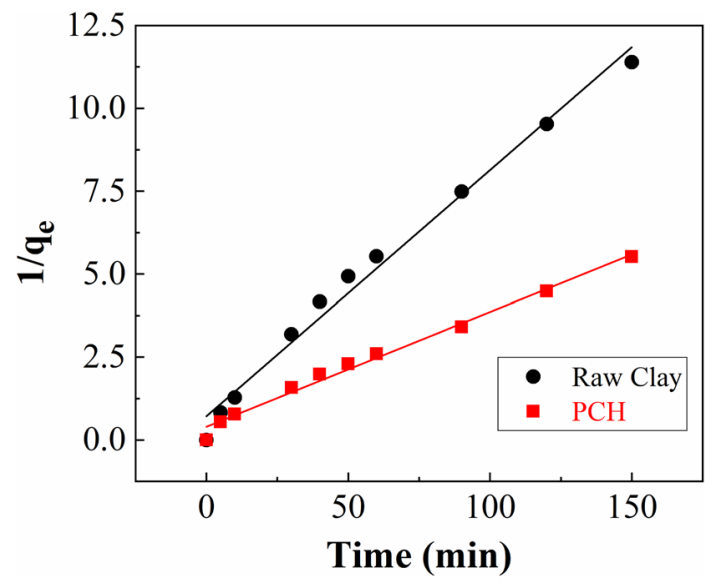

Fig. 10 Pseudo-second-order kinetic model of Glyphosate adsorption on Natural clay and $\mathrm{PCH}$

It was observed that the pseudo second- order model better represented the adsorption kinetics and the calculated $\mathrm{q}_{\mathrm{e}}$ values agreed with the experimental $\mathrm{q}_{\mathrm{e}}$ values (Table 3). This suggests that the adsorption of glyphosate follows second order kinetics with both natural clay and $\mathrm{PCH}$. The correlation coefficient value of the pseudo-first order kinetic equation is slightly lower than the pseudo-second order kinetic equation, indicating that this adsorption is mainly controlled by the surface control, rather than the adsorbate diffusion (Chen et al. 2016).

\section{Equilibrium modeling}

Figure 11 shows the adsorption isotherms of glyphosate on the starting clay and the $\mathrm{PCH}$. The isotherms of both adsorbents are of type I. The isotherms have a marked initial slope that meaning at low concentration the materials are more efficient. The saturation of adsorbent is related to the occupation of adsorption sites. These data reveal that glyphosate adsorption on natural clay is about $13.2 \mathrm{mg} / \mathrm{g}$ while PCH displays higher adsorption values $(25.5 \mathrm{mg} / \mathrm{g})$ under similar conditions. The greater adsorption capacity of the PCH could be ascribed to a higher affinity due to its textural properties with a larger surface area and a high number of micropores. It is a consequence of the formation of $\mathrm{SiO}_{2}$ pillar and the delamination of the clay sheets (Cecilia et al. 2013) in such a way this adsorbent can capture glyphosate molecules in its porous structure. The adsorption capacity of $\mathrm{PCH}$ is above other clay minerals although these values are below biochars and some soils (Table 4).

To carry out a more detailed study of the adsorption isotherms, both isotherms were fitted to Langmuir, Freundlich and Temkin models.

The plotting $\left(\mathrm{C}_{\mathrm{e}} / \mathrm{q}_{\mathrm{e}}\right)$ versus $\left(\mathrm{C}_{\mathrm{e}}\right)$, $\left(\operatorname{lnq}_{\mathrm{e}}\right)$ versus $\left(\operatorname{lnC}_{\mathrm{e}}\right)$ and $\left(\mathrm{q}_{\mathrm{e}}\right)$ vs $\left(\operatorname{lnC}_{\mathrm{e}}\right)$, it is possible to determine the constants of 
Table 3 Kinetic adsorption parameters according to the pseudo first and secondorder models for Glyphosate adsorption

\begin{tabular}{|c|c|c|c|c|c|c|c|}
\hline \multirow[t]{2}{*}{ Material } & \multirow[t]{2}{*}{$\mathrm{q}_{\mathrm{e}, \exp }(\mathrm{mg} / \mathrm{g})$} & \multicolumn{3}{|c|}{ Pseudo-first-order kinetic model } & \multicolumn{3}{|c|}{$\begin{array}{l}\text { Pseudo-second-order kinetic } \\
\text { model }\end{array}$} \\
\hline & & $\mathrm{k}_{1}\left(\min ^{-1}\right)$ & $\mathrm{q}_{\mathrm{e}}(\mathrm{mg} / \mathrm{g})$ & $\mathrm{R}^{2}$ & $\mathrm{k}_{2}\left(\min ^{-1}\right)$ & $\mathrm{q}_{\mathrm{e}}(\mathrm{mg} / \mathrm{g})$ & $\mathrm{R}^{2}$ \\
\hline Natural clay & 13.5 & 0.021 & 9.18 & 0.96 & 0.0076 & 13.5 & 0.99 \\
\hline $\mathrm{PCH}$ & 27.5 & 0.029 & 22.37 & 0.97 & 0.0029 & 28.9 & 0.98 \\
\hline
\end{tabular}

such model adsorption models. These constants are listed in Table 5.

The equilibrium data have been well described using the Langmuir model (Fig. 12) for the two materials with a correlation coefficient $\mathrm{R}^{2}$ equal to 0.996 and 0.976 for the natural clay and the PCH respectively (Table 5). With Langmuir model, it assumes that glyphosate molecules are adsorbed on natural clay or PCH with monolayer adsorption in homogeneous adsorption sites. According to this model, the maximum adsorption capacity $\left(\mathrm{Q}_{0}\right)$ of the natural clay was 12.84 and $26.35 \mathrm{mg} / \mathrm{g}$ for the $\mathrm{PCH}$, respectively. These data are close to the experimental values of maximum adsorption capacities. With regard to the $\mathrm{b}$ coefficient, which defines the interaction between adsorbate (glyphosate) and the adsorbent (natural clay or $\mathrm{PCH}$ ), it can be observed that $\mathrm{PCH}$ displays a higher value in its parameter $b\left(0.22 \mathrm{~L} \mathrm{mg}^{-1}\right)$ in comparison to the raw clay $\left(0.02 \mathrm{~L} \mathrm{mg}^{-1}\right)$ (Table 5). This fact indicates that the interaction $\mathrm{PCH}$-glyphosate- $\mathrm{PCH}$ is stronger with those observed in the case glyphosate-raw clay. Taking into account the textural properties and the characterization of the materials after the adsorption tests, it can be concluded that the interaction of the $\mathrm{PCH}$ with glyphosate in the microporous is stronger than the interaction natural clay with glyphosate, which is intercalated in the interlayer spacing as was deduced from XRD data (Fig. 2). The $R_{L}$ values of natural clay and $\mathrm{PCH}$ are 0.3 and 0.04 respectively. This indicates that the adsorption of glyphosate on the natural clay and the $\mathrm{PCH}$ is favorable. From these data, it can be inferred that the $\mathrm{PCH}$ can be very useful for the removal of glyphosate from water.

The Freundlich model is very useful to determinate the heterogeneity of the adsorption sites (Fig. 13 and Table 6). $\mathrm{K}_{\mathrm{f}}$ value, which defines the adsorption capacity of the sorbent, shows how $\mathrm{PCH}$ displays higher $\mathrm{K}_{\mathrm{f}}$ values $(5.26 \mathrm{~L} / \mathrm{mg}$ ) than natural clay one $(2.38 \mathrm{~L} / \mathrm{mg})$. The values of the $1 / \mathrm{n}$ factor obtained from the Freundlich model are below unity in both cases $(0.448$ for natural clay and 0.409 for $\mathrm{PCH})$. This fact indicates that, despite the adsorption isotherms were well-fitted to the Langmuir model; the adsorption sites are highly heterogeneous.

For the Temkin model (Fig. 14), the values of the heat of adsorption $\left(\mathrm{b}_{\mathrm{T}}\right)$ are equals to 4.259 and $6.472 \mathrm{~kJ} / \mathrm{mol}$ for raw clay and $\mathrm{PCH}$, respectively. The value of the correlation factors (Table 7) confirms that the Temkin model is adequate for the adsorption of glyphosate by both adsorbents.
After adsorption studies, both natural clay and $\mathrm{PCH}$ were recovered and analyzed by several experimental techniques. From the study of the samples by XRD, it can be observed how the diffraction profile of the natural clay shows slight differences between before and after the adsorption process (Fig. 15). Thus, it can be observed how some peaks ascribed to impurities of the clay disappear after the glyphosate adsorption. However, the most striking fact is the displacement of the basal reflection $\left(\mathrm{d}_{001}\right)$ to lower $2 \theta$ values. This implies that glyphosate molecules tend to be introduced into the interlamellar spacing of smectite. On the other hand, no clear changes are observed in the diffraction profile of $\mathrm{PCH}$ after the adsorption process.

After adsorption process, it is expected that a slight change in the chemical composition on the surface could be observed both natural clay and PCH so XPS analysis were carried out (Table 2). These data show that the typical contributions of natural clay and $\mathrm{PCH}$ are maintained although it is noticeable a slight increase of the C-content on the surface of both samples, which could confirm the adsorption of glyphosate on their surface.

\section{Temperature effect in the glyphosate adsorption on $\mathrm{PCH}$}

To understand the thermodynamic phenomenon of glyphosate adsorption on $\mathrm{PCH}$, pesticide removal experiments

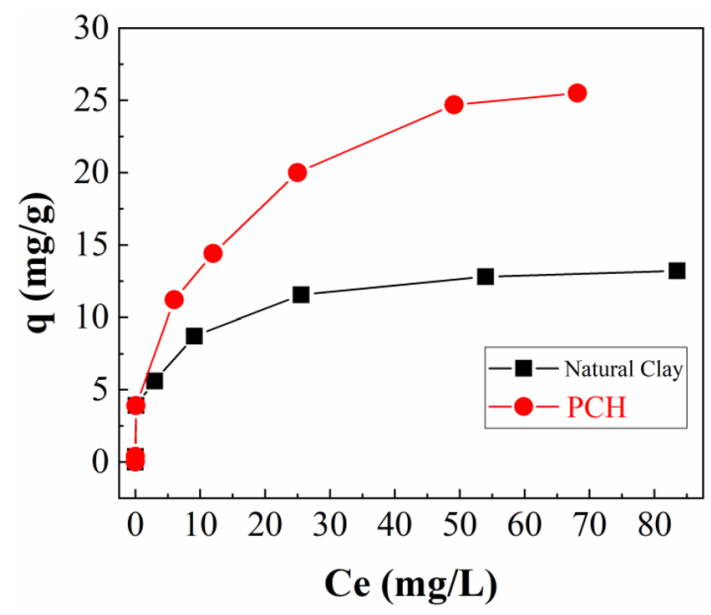

Fig. 11 Adsorption isotherms of Glyphosate onto Natural clay and PCH using an initial Glyphosate concentration (0.5-100 ppm) at $\mathrm{pH}=8$ and $\mathrm{T}=25^{\circ} \mathrm{C}$ 
Table 4 Comparison between the glyphosate adsorption shown in the present work with that reported in the literature

\begin{tabular}{|c|c|c|c|c|}
\hline Adsorbent & $\mathrm{pH}$ & $\begin{array}{l}\text { Temperature } \\
\left({ }^{\circ} \mathrm{C}\right)\end{array}$ & Qe $(\mathrm{mg} / \mathrm{g})$ & References \\
\hline Goethite & 7.0 & 25 & 7.9 & Yang et al. (2018b) \\
\hline Goethite & 7.0 & 25 & 21.6 & McConnell and Hossner (1985) \\
\hline Magnetite & 7.0 & 25 & 6.7 & Yang et al. (2018b) \\
\hline Ferrihydrate $+\mathrm{NaCl}$ & 5.0 & 25 & 33 & Pereira et al. (2019) \\
\hline Hematite & 7.0 & 25 & 7.9 & McConnell and Hossner (1985) \\
\hline Forest soil & 12.0 & 30 & 161 & Sen et al. (2017) \\
\hline Soil & 5.9 & 20 & 21 & Gimsing et al. (2007) \\
\hline Biochar & 5.0 & 20 & 44 & Mayakaduwa et al. (2016) \\
\hline Biochar & 2.0 & 30 & 35 & Jiang et al. (2018) \\
\hline $\mathrm{Fe} /$ carbon nanotubes & 4.0 & 25 & 44 & Diel et al. (2021) \\
\hline $\mathrm{MnFe}_{2} \mathrm{O}_{4}$-graphene & 4.7 & 25 & 39 & Yamaguchi et al. (2016) \\
\hline $\begin{array}{l}\mathrm{MnFe}_{2} \mathrm{O}_{4} @ \text { celullose acti- } \\
\text { vated carbon }\end{array}$ & 3.4 & 25 & 167 & Chen et al. (2019) \\
\hline $\mathrm{MnFe}_{2} \mathrm{O}_{4}$ nanoparticles & 3.4 & 25 & 93 & Chen et al. (2019) \\
\hline Montmorillonite & 4.0 & 25 & 4.5 & Glass (1987) \\
\hline Illite & 4.0 & 25 & 2 & Glass (1987) \\
\hline Kaolinite & 4.0 & 25 & 1 & Glass (1987) \\
\hline Montmorillonite & 4.0 & 25 & 5.2 & da Cruz et al. (2007) \\
\hline Kaolinite & 4.0 & 25 & 6.5 & da Cruz et al. (2007) \\
\hline Bentonite & 4.0 & 25 & 9.3 & da Cruz et al. (2007) \\
\hline Florai soil & 4.0 & 25 & 0.4 & da Cruz et al. (2007) \\
\hline Tibagi soil & 4.0 & 25 & 2.6 & da Cruz et al. (2007) \\
\hline Londrina soil & 4.0 & 25 & 6.4 & da Cruz et al. (2007) \\
\hline Smectite & 8.0 & 25 & 13 & This work \\
\hline $\mathrm{PCH}$ & 8.0 & 25 & 26 & This work \\
\hline
\end{tabular}

were performed varying the temperature of the contaminated solutions from 25 to $65^{\circ} \mathrm{C}$. From these data, it can be observed an increase of the glyphosate adsorption when the tempereture also increases Fig. 16. These data are in agreement with those reported in another study where glyphosate was adsorbed on an anionic exchange resin (Chen et al. 2016). Within the porous structure of the PCH the barrier of activation energy is overcome, which leads to the increase in the amount of the adsorbed pesticide.

The changes of enthalpy $\left(\Delta \mathrm{H}^{\circ}\right)$, entropy $\left(\Delta \mathrm{S}^{\circ}\right)$ and the Gibbs free energy $\left(\Delta \mathrm{G}^{\circ}\right)$ were determined using the following equations:

$\Delta G=-R T \ln K_{c}$

Table 5 Equilibrium adsorption parameters according to Langmuir model

\begin{tabular}{lllll}
\hline Adsorbent & $\mathrm{Q}_{0}(\mathrm{mg} / \mathrm{g})$ & $\mathrm{b}(\mathrm{L} / \mathrm{mg})$ & $\mathrm{R}^{2}$ & $\mathrm{RMSE}$ \\
\hline Natural Clay & 12.84 & 0.02 & 0.996 & $1.85 \mathrm{E}-7$ \\
PCH & 26.35 & 0.22 & 0.976 & $1.85 \mathrm{E}-7$ \\
\hline
\end{tabular}

$\ln K_{c}=\frac{\Delta S}{R}-\frac{\Delta H}{R T}$

where $\mathrm{R}$ is the universal gas constant, $\mathrm{T}$ the absolute temperature and $\mathrm{K}_{\mathrm{c}}$ is the adsorption constant (Garshasbi et al.

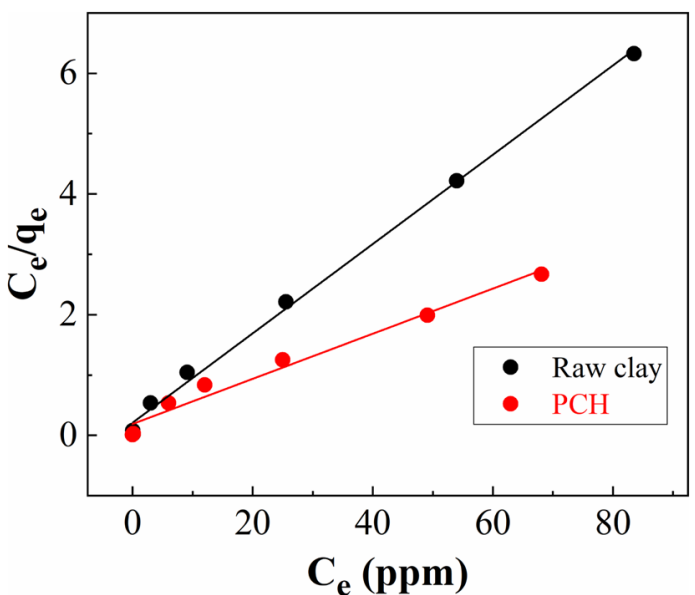

Fig. 12 Langmuir adsorption isotherm of glyphosate on Natural Clay and $\mathrm{PCH}$ 
Table 6 Equilibrium adsorption parameters according to Freundlich model

\begin{tabular}{lllll}
\hline Adsorbent & $\mathrm{K}_{\mathrm{f}}(\mathrm{L} / \mathrm{mg})$ & $\mathrm{n}$ & $\mathrm{R}^{2}$ & $\mathrm{RMSE}$ \\
\hline Natural Clay & 2.38 & 2.23 & 0.796 & $4.27 \mathrm{E}-3$ \\
PCH & 5.26 & 2.44 & 0.95 & $1.19 \mathrm{E}-4$ \\
\hline
\end{tabular}

Table 7 Equilibrium adsorption parameters according to Temkin model

\begin{tabular}{lllll}
\hline Adsorbent & $\mathrm{A}(\mathrm{L} / \mathrm{g})$ & $\mathrm{B}$ & $\mathrm{R}^{2}$ & $\mathrm{RMSE}$ \\
\hline Natural Clay & 14.087 & 1.731 & 0.976 & $1.85 \mathrm{E}-5$ \\
PCH & 83.58 & 2.63 & 0.887 & $9.48 \mathrm{E}-4$ \\
\hline
\end{tabular}

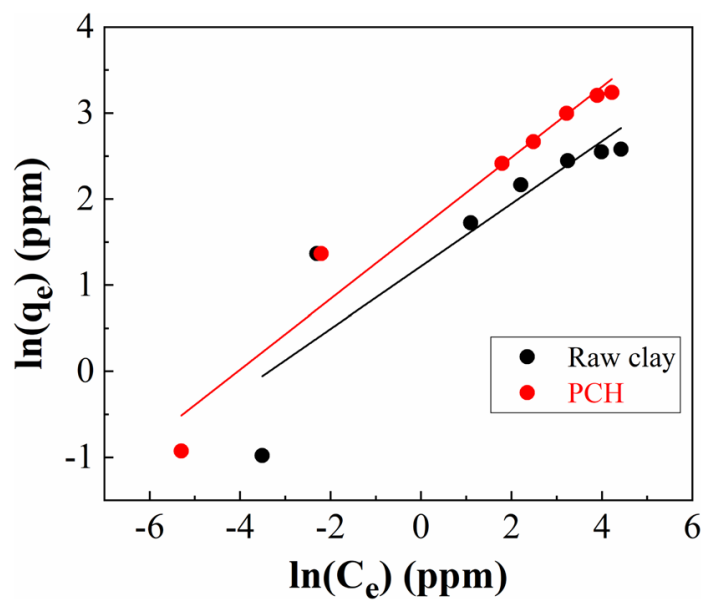

Fig. 13 Freundlich adsorption isotherm of glyphosate on Natural Clay and $\mathrm{PCH}$

2017). The thermodynamic parameters were calculated by plotting $\ln \mathrm{K}_{\mathrm{c}}=\mathrm{f}(1 / \mathrm{T})$.

Table 8 presents the values of the thermodynamic parameters $\left(\Delta \mathrm{G}^{\circ}, \Delta \mathrm{H}^{\circ}\right.$ and $\left.\Delta \mathrm{S}^{\circ}\right)$ for glyphosate adsorption on $\mathrm{PCH}$. From these data, it can be inferred that the adsorption is an endothermic process $\left(\Delta \mathrm{H}^{\circ}>0\right)$. When $\Delta \mathrm{H}^{\circ}$ is in the range of $5-10 \mathrm{~kJ} \mathrm{~mol}^{-1}$, the adsorption mechanism is physisorption; i.e., the bond between adsorbent and adsorbate is mainly due to van der Waals interactions. However, if $\Delta \mathrm{H}^{\circ}$ is in the range of $30-70 \mathrm{~kJ} \mathrm{~mol}^{-1}$, the adsorption belongs to chemisorption; i.e., a chemical bond is formed between the adsorbate and the surface. In the present system, the value of $\Delta \mathrm{H}^{\circ}$ indicates that the adsorption is eminently physical so it is favored when the temperature increases $(\mathrm{Li}$ and $\mathrm{Li}$ 2009; Yan et al. 2008).

$\Delta \mathrm{S}^{\circ}$ is also positive so the degree of freedom increases at the solid-liquid interface during the adsorption process. The negative value of $\Delta \mathrm{G}^{\circ}$ of the $\mathrm{PCH}$-glyphosate system

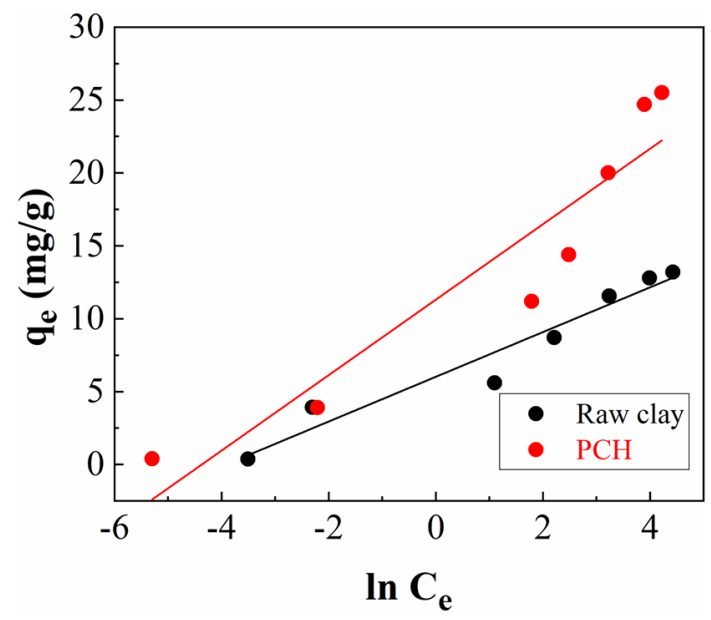

Fig. 14 Temkin adsorption isotherm of Glyphosate on Natural Clay (NC) and $\mathrm{PCH}$

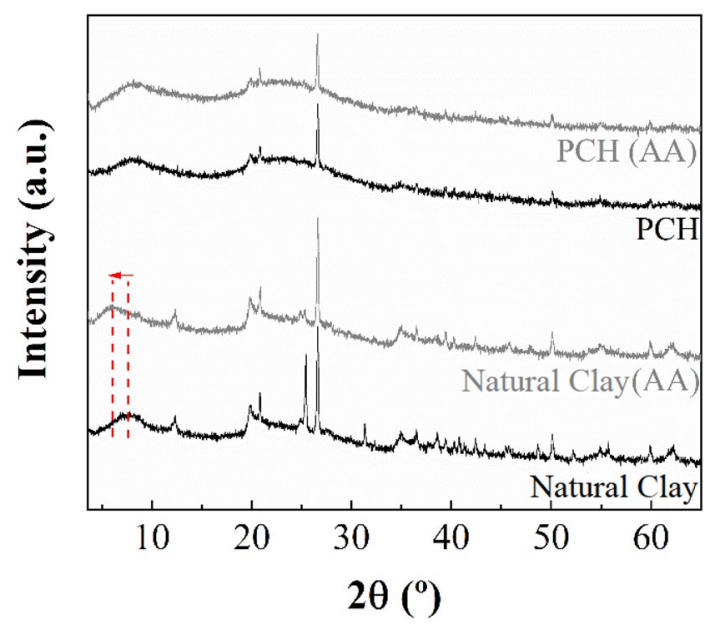

Fig. 15 XRD pattern of the Natural Clay and PCH before and after glyphosate adsorption

indicates that the reaction is spontaneous. It can be noted that the value of $\Delta \mathrm{G}^{\circ}$ decreases with increasing of the temperature, which can be explained by the fact that the adsorption becomes easier and favored when the temperature becomes very high so the degree of spontaneity of the thermodynamic reaction increases.

\section{Conclusions}

Bentonite is an effective precursor for synthesizing PCHs for glyphosate removal, concluding that these adsorbents can remove herbicides remaining in agricultural wastewater. The maximum amount of adsorbed glyphosate is almost doubled 


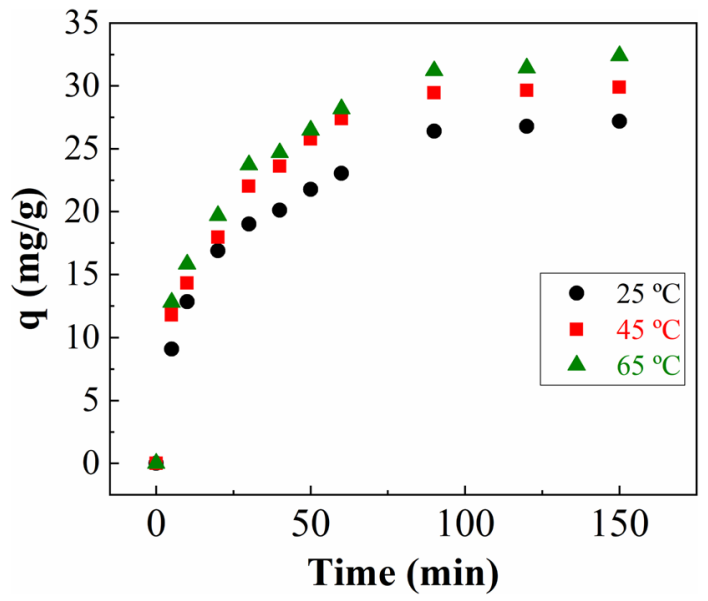

Fig. 16 Effect of the temperature on the removal of glyphosate onto $\mathrm{Si}-\mathrm{PCH}\left(\mathrm{pH}=8, \mathrm{~m}=40 \mathrm{mg}\right.$ and $\left.\mathrm{C}_{\mathrm{i}}=100 \mathrm{ppm}\right)$

Table 8 Thermodynamic parameters for the Glyphosate adsorption onto $\mathrm{Si}-\mathrm{PCH}$

\begin{tabular}{llll}
\hline $\begin{array}{l}\text { Temperature } \\
\left({ }^{\circ} \mathrm{C}\right)\end{array}$ & $\Delta \mathrm{G}^{\circ}(\mathrm{kJ} / \mathrm{mol})$ & $\Delta \mathrm{H}^{\circ}(\mathrm{kJ} / \mathrm{mol})$ & $\Delta \mathrm{S}^{\circ}(\mathrm{J} / \mathrm{Kmol})$ \\
\hline 25 & -0.89 & 8.5 & 29.88 \\
40 & -0.599 & & \\
50 & -0.105 & & \\
\hline
\end{tabular}

with PCH from $13.5 \mathrm{mg} / \mathrm{g}$ of natural clay to $27.5 \mathrm{mg} / \mathrm{g}$ of $\mathrm{PCH}$.

The adsorption process takes place through an interaction between silanol groups of montmorillonite and/or of the $\mathrm{PCH}$ adsorbent with glyphosate. This adsorption is influenced by the $\mathrm{pH}$ of the system and the amount of adsorbent. The experimental results of the adsorption confirmed that PCH has a higher glyphosate adsorption capacity than natural clay.

Due to the vast existence of mineral clays and the simple processing for the synthesis of $\mathrm{PCH}$, it is expected to have a significant impact on the fate of pesticides and other organic pollutants in the environment. Therefore, the mechanistic study of the adsorption of glyphosate on $\mathrm{PCH}$ may provide new insight into the fate of contaminants in the environment.

Acknowledgements This study was partially funded by project RTI2018-099668-BC22 of Ministerio de Ciencia, Innovación y Universidades, and project UMA18-FEDERJA-126 of Junta de Andalucía and FEDER funds.

Funding Open Access funding provided thanks to the CRUE-CSIC agreement with Springer Nature and Funding for open access charge: Universidad de Málaga / CBUA.
Open Access This article is licensed under a Creative Commons Attribution 4.0 International License, which permits use, sharing, adaptation, distribution and reproduction in any medium or format, as long as you give appropriate credit to the original author(s) and the source, provide a link to the Creative Commons licence, and indicate if changes were made. The images or other third party material in this article are included in the article's Creative Commons licence, unless indicated otherwise in a credit line to the material. If material is not included in the article's Creative Commons licence and your intended use is not permitted by statutory regulation or exceeds the permitted use, you will need to obtain permission directly from the copyright holder. To view a copy of this licence, visit http://creativecommons.org/licenses/by/4.0/.

\section{References}

Adeyemo AA, Adeoye IO, Bello OS (2017) Adsorption of dyes using different types of clay: a review. Appl Water Sci 7:543-568

Aguiar J, Cecilia J, Tavares P, Azevedo D, Castellón ER, Lucena S, Junior IS (2017) Adsorption study of reactive dyes onto porous clay heterostructures. Appl Clay Sci 135:35-44

Aktar W, Sengupta D, Chowdhury A (2009) Impact of pesticides use in agriculture: their benefits and hazards. Interdiscip Toxicol 2:1-12

Al-Ghouti MA, Da' ana DA (2020) Guidelines for the use and interpretation of adsorption isotherm models: a review. J Hazard Mater 393:122383

Beck JS, Vartuli J, Roth WJ, Leonowicz M, Kresge C, Schmitt K, Chu C, Olson DH, Sheppard E, McCullen S (1992) A new family of mesoporous molecular sieves prepared with liquid crystal templates. J Am Chem Soc 114:10834-10843

Brigatti MF, Galan E, Theng B (2013) Structure and mineralogy of clay minerals. Dev Clay Sci 5:21-81

Brunauer S, Emmett PH, Teller E (1938) Adsorption of gases in multimolecular layers. J Am Chem Soc 60:309-319

Cecilia J, García-Sancho C, Franco F (2013) Montmorillonite based porous clay heterostructures: Influence of $\mathrm{Zr}$ in the structure and acidic properties. Microporous Mesoporous Mater 176:95-102

Cecilia J, Arango-Díaz A, Franco F, Jiménez-Jiménez J, Storaro L, Moretti E, Rodríguez-Castellón E (2015) CuO-CeO2 supported on montmorillonite-derived porous clay heterostructures (PCH) for preferential $\mathrm{CO}$ oxidation in H2-rich stream. Catal Today 253:126-136

Cecilia J, García-Sancho C, Vilarrasa-García E, Jiménez-Jiménez J, Rodriguez-Castellón E (2018a) Synthesis, characterization, uses and applications of porous clays heterostructures: a review. Chem Rec 18:1085-1104

Cecilia JA, Pardo L, Pozo M, Bellido E, Franco F (2018b) Microwave-assisted acid activation of clays composed of 2:1 clay minerals: a comparative study. Minerals 8:376

Cecilia JA, Soriano MD, Natoli A, Rodríguez-Castellón E, López Nieto JM (2018c) Selective oxidation of hydrogen sulfide to sulfur using vanadium oxide supported on porous clay heterostructures (PCHs) formed by pillars silica, silica-zirconia or silica-titania. Materials 11:1562

Chen FX, Zhou CR, Li GP, Peng FF (2016) Thermodynamics and kinetics of glyphosate adsorption on resin D301. Arab J Chem 9:S1665-S1669

Chen Q, Zheng J, Yang Q, Dang Z, Zhang L (2019) Insights into the glyphosate adsorption behavior and mechanism by a $\mathrm{MnFe}_{2} \mathrm{O}_{4} @$ Cellulose-activated carbon magnetic hybrid. ACS Appl Mater Interfaces 11:15478-15488

Chen JL, Gao L, Jiang Q, Hou Q, Hong Y, Shen W-J, Wang Y, Zhu JH (2020) Fabricating efficient porous sorbents to 
capture organophosphorus pesticide in solution. Microporous Mesoporous Mater 294:109911

da Cruz LH, de Santana H, Zaia CTBV, Zaia DAM (2007) Adsorption of glyphosate on clays and soils from Paraná State: effect of $\mathrm{pH}$ and competitive adsorption of phosphate. Braz Arch Biol Technol 50:385-394

Dehghani MH, Niasar ZS, Mehrnia MR, Shayeghi M, Al-Ghouti MA, Heibati B, McKay G, Yetilmezsoy K (2017) Optimizing the removal of organophosphorus pesticide malathion from water using multi-walled carbon nanotubes. Chem Eng J 310:22-32

Diel JC, Franco DSP, Nunes IS, Pereira HA, Moreira KS, Burgo TAL, Foletto EL, Dotto GL (2021) Carbon nanotubes impregnated with metallic nanoparticles and their application as an adsorbent for the glyphosate removal in an aqueous matrix. J Environ Chem Eng 9:105178

Eto M (1974) Organophosphorus pesticides: organic and biological chemistry. CRC Press, Cleveland, pp 254-255

Farmer VC (1974) Infrared spectra of minerals. Mineralogical Society, London

Ferreira P, Nunes C, Pires J, Carvalho AP, Brandao P, Rocha J (2006) Hydrophobic porous benzene-silica hybrid clay heterostructure and its application in the adsorption of volatile organic compounds. Mater Sci Forum 514:470-474

Franco F, Pozo M, Cecilia JA, Benítez-Guerrero M, Lorente M (2016) Effectiveness of microwave assisted acid treatment on dioctahedral and trioctahedral smectites. The influence of octahedral composition. Appl Clay Sci 120:70-80

Galarneau A, Barodawalla A, Pinnavaia TJ (1995) Porous clay heterostructures formed by gallery-templated synthesis. Nature 374:529-531

Gârea S, Mihai A, Ghebaur A, Nistor C, Sârbu A (2015) Porous clay heterostructures: a new inorganic host for 5-fluorouracil encapsulation. Int J Pharm 491:299-309

Garea S, Mihai A, Vasile E, Nistor C, Sarbu A, Mitran R (2016) Synthesis of new porous clay heterostructures: the influence of cosurfactant type. Mater Chem Phys 179:17-26

Garshasbi V, Jahangiri M, Anbia M (2017) Equilibrium $\mathrm{CO}_{2}$ adsorption on zeolite $13 \mathrm{X}$ prepared from natural clays. Appl Surf Sci 393:225-233

Gimsing AL, Szilas C, Borggaard OK (2007) Sorption of glyphosate and phosphate by variable-charge tropical soils from Tanzania. Geoderma 138:127-132

Glass RL (1987) Adsorption of glyphosate by soils and clay minerals. J Agric Food Chem 35:497-500

Halim AA, Aziz HA, Johari MAM, Ariffin KS (2010) Comparison study of ammonia and COD adsorption on zeolite, activated carbon and composite materials in landfill leachate treatment. Desalination 262:31-35

Hamza RA, Iorhemen OT, Tay JH (2016) Occurrence, impacts and removal of emerging substances of concern from wastewater. Environ Technol Innov 5:161-175

Hayes AL, Wise R, Weir F (1980) Assessment of occupational exposure to organophosphates in pest control operators. Am Ind Hyg Assoc J 41:568-575

Herath GAD, Poh LS, Ng WJ (2019) Statistical optimization of glyphosate adsorption by biochar and activated carbon with response surface methodology. Chemosphere 227:533-540

Jamali A, Shemirani F, Morsali A (2019) A comparative study of adsorption and removal of organophosphorus insecticides from aqueous solution by Zr-based MOFs. J Ind Eng Chem 80:83-92

Jariyal M, Gupta V, Jindal V, Mandal K (2015) Isolation and evaluation of potent Pseudomonas species for bioremediation of phorate in amended soil. Ecotoxicol Environ Saf 122:24-30

Jiang X, Ouyang Z, Zhang Z, Yang C, Li X, Dang Z, Wu P (2018) Mechanism of glyphosate removal by biochar supported nano-zero-valent iron in aqueous solutions. Colloids Surf A 547:64-72

Khan FI, Husain T, Hejazi R (2004) An overview and analysis of site remediation technologies. J Environ Manag 71:95-122

Khoury GA, Gehris TC, Tribe L, Sánchez RMT, dos Santos Afonso M (2010) Glyphosate adsorption on montmorillonite: An experimental and theoretical study of surface complexes. Appl Clay Sci 50:167-175

Landers J, Gor GY, Neimark AV (2013) Density functional theory methods for characterization of porous materials. Colloids Surf A 437:3-32

Li QQ, Li WM (2009) Study on thermodymamics of adsorbing timosaponin by resin. J Liaoning Univ Tradit Chin Med 6:

Lippens BC, De Boer J (1965) Studies on pore systems in catalysts: V. The t method. J Catal 4:319-323

Madejová J (2003) FTIR techniques in clay mineral studies. Vib Spectrosc 31:1-10

Marican A, Durán-Lara EF (2018) A review on pesticide removal through different processes. Environ Sci Pollut Res 25:2051-2064

Mayakaduwa SS, Kumarathilaka P, Herath I, Ahmad M, Al-Wabel M, Ok YS, Usman A, Abduljabbar A, Vithanage M (2016) Equilibrium and kinetic mechanisms of woody biochar on aqueous glyphosate removal. Chemosphere 144:2516-2521

McConnell JS, Hossner LR (1985) pH-dependent adsorption isotherms of glyphosate. J Agric Food Chem 33:1075-1078

Nunes CD, Pires J, Carvalho AP, Calhorda MJ, Ferreira P (2008) Synthesis and characterisation of organo-silica hydrophobic clay heterostructures for volatile organic compounds removal. Microporous Mesoporous Mater 111:612-619

Odukkathil G, Vasudevan N (2013) Toxicity and bioremediation of pesticides in agricultural soil. Rev Environ Sci Biotechnol 12:421-444

Omri A, Wali A, Benzina M (2016) Adsorption of bentazon on activated carbon prepared from Lawsonia inermis wood: Equilibrium, kinetic and thermodynamic studies. Arab J Chem 9:S1729-S1739

Pereira RC, Anizelli PR, di Mauro E, Valezi DF, da Costa ACS, Zaia CTBV, Zaia DAM (2019) The efect of $\mathrm{pH}$ and ionic strength on the adsorption of glyphosate onto ferrihydrite. Geochem Trans $20: 3$

Pires J, Araujo A, Carvalho A, Pinto M, Gonzalez-Calbet J, RamırezCastellanos J (2004) Porous materials from clays by the gallery template approach: synthesis, characterization and adsorption properties. Microporous Mesoporous Mater 73:175-180

Pires J, Bestilleiro M, Pinto M, Gil A (2008) Selective adsorption of carbon dioxide, methane and ethane by porous clays heterostructures. Sep Purif Technol 61:161-167

Sarkar S, Das R (2017) PVP capped silver nanocubes assisted removal of glyphosate from water-a photoluminescence study. J Hazard Mater 339:54-62

Sen K, Mondal NK, Chattoraj S, Datta JK (2017) Statistical optimization study of adsorption parameters for the removal of glyphosate on forest soil using the response surface methodology. Environ Earth Sci 76:22

Suo F, Xie G, Zhang J, Li J, Li C, Liu X, Zhang Y, Ma Y, Ji M (2018) A carbonised sieve-like corn straw cellulose-graphene oxide composite for organophosphorus pesticide removal. RSC Adv 8:7735-7743

Thommes M, Kaneko K, Neimark AV, Olivier JP, Rodriguez-Reinoso F, Rouquerol J, Sing KS (2015) Physisorption of gases, with special reference to the evaluation of surface area and pore size distribution (IUPAC Technical Report). Pure Appl Chem 87:1051-1069

Vaccari A (1999) Clays and catalysis: a promising future. Appl Clay Sci 14:161-198

Vilarrasa-García E, Cecilia J, Azevedo D, Cavalcante C Jr, RodríguezCastellón E (2017) Evaluation of porous clay heterostructures 
modified with amine species as adsorbent for the $\mathrm{CO} 2$ capture. Microporous Mesoporous Mater 249:25-33

Wang S, Seiwert B, Kästner M, Miltner A, Schäffer A, Reemtsma T, Yang Q, Nowak KM (2016) (Bio) degradation of glyphosate in water-sediment microcosms-a stable isotope co-labeling approach. Water Res 99:91-100

Wilkinson CF, Wilkinson CF (1976) Insecticide biochemistry and physiology. Springer, New York

Yamaguchi NU, Bergamasco R, Hamoudi S (2016) Magnetic $\mathrm{MnFe}_{2} \mathrm{O}_{4}$-graphene hybrid composite for efficient removal of glyphosate from wáter. Chem Eng J 295:391-402

Yan L, Min Y, Hong-bin W (2008) Study on thermodynamics of soil adsorbing glyphosate. J Anhui Agric Sci 23:*

Yang Q, Wang J, Zhang W, Liu F, Yue X, Liu Y, Yang M, Li Z, Wang $\mathbf{J}$ (2017) Interface engineering of metal organic framework on graphene oxide with enhanced adsorption capacity for organophosphorus pesticide. Chem Eng J 313:19-26

Yang Q, Wang J, Chen X, Yang W, Pei H, Hu N, Li Z, Suo Y, Li T, Wang J (2018a) The simultaneous detection and removal of organophosphorus pesticides by a novel $\mathrm{Zr}$-MOF based smart adsorbent. Journal of Materials Chemistry A 6:2184-2192

Yang Y, Deng Q, Yan W, Jing C, Zhang Y (2018b) Comparative study of glyphosate removal on goethite and magnetite: adsorption and photo-degradation. Chem Eng J 352:581-589

Zare M, Ramezani Z, Rahbar N (2016) Development of zirconia nanoparticles-decorated calcium alginate hydrogel fibers for extraction of organophosphorous pesticides from water and juice samples: facile synthesis and application with elimination of matrix effects. J Chromatogr A 1473:28-37

Zhu R, Chen Q, Zhou Q, Xi Y, Zhu J, He H (2016) Adsorbents based on montmorillonite for contaminant removal from water: a review. Appl Clay Sci 123:239-258

Zviagina BB, McCarty DK, Środoń J, Drits VA (2004) Interpretation of infrared spectra of dioctahedral smectites in the region of $\mathrm{OH}-$ stretching vibrations. Clays Clay Miner 52:399-410

Publisher's Note Springer Nature remains neutral with regard to jurisdictional claims in published maps and institutional affiliations. 